\title{
Transport component in the price of goods
}

\author{
Vera Baginova $^{1, *}$ and Lev Fedorov ${ }^{1}$ \\ ${ }^{1}$ Russian University of Transport (Moscow Institute of Railway Engineers (MIIT), 9 Obraztsova St., \\ Building 9, 127994, Moscow, Russia
}

\begin{abstract}
The main aspects of the transport component in the price of goods are considered. The analysis of cost and statistical general transport in-kind indicators characterizing the role of transport in economic relations is carried out. Disadvantages of these indicators are identified. The suggestions on their elimination and improvement of accounting for transport costs in the cost structure of the transport component are presented. It is indicated that the implementation of the proposals will make it possible to more correctly determine the transport component and identify the dynamics of proportions in the development of transport and other sectors of the country's economy.
\end{abstract}

\section{Introduction}

The transition of the Russian economy to the market raises the question of the relationship of transport and the distribution sphere as a whole with commodity-money relations. The main purpose and content of the latter lies in the inextricable interweaving of two functions - the exchange itself and the measurement of labor costs and results based on it in accordance with the principle of "each gets according to the results of labor". Such a formulation of the question lies in the trajectory of the development of world economic scientific thought, reflecting the evolution of the economy itself and acting as a solution to the problem of the interaction of production and exchange.

Transport, carrying out the transportation of goods between suppliers and consumers, performs an important function of the relationship between production and circulation. The role of transport in these relationships is primarily determined by the share of the transport component in the price of the finished product demand from end consumers and in the costs of export shippers (not to be equated with transport costs, which are the operating costs of transport companies). From this it follows that the transport component (in the narrow sense of the transport factor) significantly affects the competitiveness of goods and should be in the focus of attention of regulatory central and sectoral authorities. Neglect of this indicator to some extent can lead to errors in the development of transport policy. Conversely, strategic decisions can increase the share of the transport component. Thus, the

\footnotetext{
* Corresponding author: vvbaginova@gmail.com
} 
liquidation of the unified transport system of the USSR, accompanied by an increase in tariffs for the transport of foreign trade goods through the territory of the CIS countries, the opening of new border transport crossings and national customs, led to an increase in the share of the transport component in the price of goods to $40-60 \%$ and a decrease in their competitiveness in the international market.

\section{Materials and methods}

For the purpose of competent regulation of the transport component, it is necessary to possess relevant information. However, the current statistical information in Russia contains only general transport indicators that are reducible to the volume of cargo transported in tons and completed ton-kilometers by mode of transport. These indicators do not reflect the structure of transportation by type of cargo and, therefore, their economic nature, i.e. which part of the total volume of traffic characterizes economic relations, which part - intra-production and international traffic. And, therefore, this statistical information cannot serve as the basis for determining the transport component. Based on such information, it is impossible to identify the role and place of transport in general and its individual types in the country's economy.

I.V. Kochetov, examining the issues of general transport statistics, wrote: "If you divide the reduced freight turnover into transported tons, then the obtained range does not have economic value; it does not characterize the average distance between the place of departure and arrival of goods, since large masses of goods were transported in fact in mixed traffic (with the participation of two or more types of transport along the entire route).

It is not possible to have the economically correct range of transportation even if the cargo turnover ... is divided by the physical volume of production of economy sectors of the same year. The range of transportation of goods obtained in the latter case is incorrect due to the incompatibility of the numerator and denominator: a large proportion of the turnover relates to imports, international transit and technological transportation ... (these are in-plant transportation related to the technology of the production process or within the transport itself as an industry (non-revenue traffic carried out not according to general transportation documents and tariffs); or to ensure the production process in other industries; or the movement of nature resources that are not products of sectors of the national economy to places of production or personal consumption; or the removal of waste, garbage, etc.

Thus, the volume of transportation includes not only transportation characterizing material ties in the sphere of circulation between sectors of the national economy (economic transportation), but also internal production (technological), as well as transportation of goods that are not included in the composition of the national products (transportation of building soil, overburden, snow, water, transportation of fuel, raw materials from workshop to workshop, from warehouses to workshops, etc.)". [1-3]

As for the indicators on the basis of which it is possible to determine economic ties and the transport component by type of cargo and mode of transport (sender, recipient, point of departure, destination, type of cargo, freight charge, price of goods, etc.), then they are reflected only in the primary reporting documents. As a result of which there is an underutilization of its potential to give answers to many questions that arise, in particular, in the field of management and scientific activities in transport. In addition, the received income, which is reflected in the primary reporting documents on the current indicators of transported tons and completed ton-kilometers, as I.V. Kochetov noted in the aforementioned scientific work, "is complicated, since they reflect not only the formation of national income, but also its expenditure, distribution and redistribution". Domestic prices for goods published by Rosstat (Russian Federal State Statistics Service) are mainly 
only producer prices and require appropriate calculations, which to some extent reduces the reliability of the final price of the goods and the share of the transport component in it.

In practice, in order to obtain information about the transport component, they often apply for various kinds of instructions. An example of this, in particular, is the order of the Government of the Russian Federation of 2016 to the Ministry of Economy, the Ministry of Transport, the Federal Antimonopoly Service, JSC Russian Railways, and the council of consumers of the services of this joint-stock company to develop proposals for the maximum permissible levels of transport component in the prices of various cargoes. The government, controlling the transport component, seeks to find its share in the price of the goods, which would not go beyond its solvency, would make it possible to identify the limit of the reserve of savings on the tariff. At the same time, this instruction to the aforementioned departments and the FSUE "Rosmorport" indicated the need to provide a methodology for estimating transport costs for various types of cargo, and the Federal Antimonopoly Service should additionally analyze the dynamics of transshipment rates for each port and check for different price conditions for independent consumers and affiliated with ports.

In turn, transport organizations put forward counter proposals to regulate the transport component. For example, in the same 2016, Russian Railways took the initiative to expand the lower border of the tariff corridor to $50 \%$. This initiative would open the possibility of providing discounts in the proposed range, balance the difference in the cost of transporting goods of various classes more correctly, and, in particular, would allow for the transportation of expensive goods at a higher tariff (third-class goods, the transport component in the price of which does not exceed 10\%) to compensate for the transportation of goods of the first class (raw materials with a transport component above 15\%) made at lower prices, and partially of goods of the second class transported at the prime cost. The share of the transport component of the latter ranges from $10 \%$ to $15 \%$ (oil, fertilizers, grain, cargo in containers). Tariff regulation also achieves other results. So, in 2012, Russian Railways together with the Federal Tariff Service, having decided to unify the tariffs for empty run of open cars, reduced their turnaround time, since after unloading, they immediately started off for loading, without waiting for the tariff for empty run to be cleared. At the same time, the latter slightly increased due to the disadvantage for operators to supply their rolling stock for loading goods that distract from the main cargo. [4]

The greatest impact on the transport component is provided by tariffs, which are based on the principle of "accounting for the solvency (usefulness) of a product". Practice shows that the largest income with this approach is achieved when the maximum is squeezed out of solvency. This clearly shows the commercial orientation of the use of tariffs based on the principle of "solvency of the goods". As for the tariff-setting method, which is based on the principle of "cost accounting", its purpose is, at a minimum, to cover the costs associated with the transportation of socially significant goods, and addition to the cost of the profit margin is necessary for the development of transport enterprises. At present, both of the above methods are applied in Russia only in railway transport. For other modes of transport, the commercial method is used for tariff setting.

The determination of the transport component in the final price of goods is a rather complicated task. One of the main difficulties in determining it is that the current statistical reporting on the transportation of goods in a consolidated form is published only by mode of transport. Such reporting does not characterize the economic connection and transport products, since a significant part of the cargo is transported in mixed traffic. The complexity of determining the transport component is also related to the fact that, for some goods transported in internal traffic, producer prices are given instead of buyer prices. This makes it necessary to calculate the conditional final price of the goods, which does not 
guarantee its coincidence with the actual market price and, as a result, leads to a deviation of the share of the transport component from its real value.

It should be noted that the category "transport products" traditionally meant and often means now the very movement (displacement) of goods (ton-kilometers) and passengers (passenger-kilometers) given by K. Marx, i.e. the work performed by transport. However, as shown by the research of N.D. Mozharov, inaccuracies were made in the definitions of transport products contained in the works of K. Marx and F. Engels when translating from German into Russian. For example, in the Russian translation, the wording of K. Marx: "Was aber die Transportin-dustrie verkauft, Ist die Ortsveranderun" (MEW, Bd.24, p.60) is pronounced as follows: "But what the transport industry sells is itself displacement" (Marx K., Engels F., Wrtings, vol. 24, p. 64). Such a translation led many specialists to the idea that K. Marx would understand the production of transport as a process of displacement. This is not true. N.D. Mozharov, taking into account the nuances of the German language, translated the above wording as follows: "But what the transport industry sells is a change in location itself", i.e. the result of the movement is nothing more than a change in the location of the cargo in space, reflecting the nature of the transport products. [5-7]

Transport costs are usually associated with the physical movement of goods, but nevertheless, as noted above, they include the costs of loading and unloading on some modes of transport, and in international traffic - also for storage, packaging, sorting, etc. In practice, it often happens that the cargo, being in rolling stock, does not move, but the ownership of it can transfer several times from one owner to another. In this regard, at least three questions arise. Is it right to include the costs of re-registration of the ownership of the goods in the transport component? Does the economic connection between the manufacturer and the buyer reflect the transactions on the change of ownership of goods that occur without moving them? Can the physical volumes of goods in such transactions reflect the development of the transport market? It seems that all three questions should be answered in the negative. Firstly, the economic connection involves the physical delivery of the goods directly to the consumer, which is not observed with the above-mentioned change of ownership of the goods. Secondly, despite the change of ownership of the goods, no transport products are created. Thirdly, re-registration of goods often can be speculative in nature.

It should not be overlooked that transportation without commodity circulation also takes place when technological, transit and irrational transportations are carried out. So, for example, commodity circulation is not observed during technological (intra-production) transportation, regardless of whether they are associated with specific technological processes of production or economic goals within the transport industry. Since in these cases, the same enterprises are the senders and receivers. Therefore, no transport products are created, and no economic connection arises.

It is important to note such a feature in the operation of railway transport in modern Russia as the return of private cars to operators with payment of a tariff for car loading capacity. Such tariffs generate income for Russian Railways and increase the costs of operators, but at the same time, transport products, as in the previous example, are not created and no economic connection arises, since only containers are paid, which in this case, compared to the cargo, is not for sale. In this regard, the question arises of the appropriateness of taking into account in the price of the goods the costs of returning those empty cars that are not served for loading in the same way. Thus, no physical movement is associated with the circulation of goods, including when the owners of cars pay for deliveries of empty cars.

\section{Results}


Based on the above analysis of the current statistical transport information and some considerations expressed during its course, a number of general main conclusions and suggestions should be made. First of all, it should be noted that this information is not adequate to address a number of tasks related to the functioning of transport in a market economy. So, the current statistical information does not contain consolidated cost indicators by mode of transport and the transport system as a whole. It also does not make it possible to obtain aggregate data, for example, on the volumes of freight and cargo turnover with respect to the entire transport complex due to the incomplete accounting of multimodal transport. The absence of such cost and in-kind indicators does not only allow us to reveal the dynamics of proportions in the development of transport and other sectors of the country's economy, but even to determine the actual range of cargo transportation. The only way out of this situation can be the improvement of the existing statistical information, taking into account the elimination of its indicated shortcomings.

The transfer of ownership of goods that take place in the practice of freight traffic without moving it, the implementation of technological transportation and transportation of natural goods, the empty mileage of a car that is not served under the load do not create transport products and economic ties. Consequently, such operations and transportation must be recognized as irrational, and the money paid for them should not be taken into account in the structure of the transport component. In order to improve statistics on the cost of transport indicators, it would be advisable to separate costs for irrational operations and transportation.

\section{References}

1. V.V. Baginova, L.S. Fedorov, E.A. Sysoeva, Logistics Monograph (Moscow, Rusains, 2016)

2. V.V. Baginova, L.S. Fedorov, S.B. Levin, Harmonization of interests as a methodological basis of logistics, Scientific Herald of the Moscow State Technical University of Civil Aviation 216 (6), 147-150 (2015)

3. V.V. Baginova, L.S. Fedorov, S.B. Levin, Logistics business: garmony of costs and results, World of Transport 12, 5(54), 112-115 (2014)

4. F. Khusainov, Operators respond to incentives, RZD-partner 17 (495), 41 (2019)

5. V.V. Baginova, L.B. Mirotin, L.S. Fedorov, S.B. Levin, Transport logistics (logistic management in transport) (2018)

6. L.S. Fedorov, D.V. Kuzmin, S.B. Levin, E.A. Sysoeva, Methodological and practical aspects of the effective work of logistics (Moscow, Knorus, 2018)

7. L.B. Mirotin, V.V. Baginova, L.S. Fedorov, Evolutionary laws of logistics, World of Transport 15, 3 (70), 56-62 (2017)

8. V.V. Baginova, Yu.M. Nerush, L.S. Fedorov, Strategy and tactics of logistics business (Moscow, Knorus, 2018)

9. L.B. Mirotin, V.V. Baginova, L.S. Fedorov, V.N. Morozov, V.I. Apatsev, Logistics methods as a management efficiency factor, Competitiveness in the global world: economics, science, technologies 2-3 (31), 91-98 (2017) No. 2-3 (31) 